\title{
Rock magnetic criteria for the detection of biogenic magnetite
}

\author{
Bruce M. Moskowitz a , Richard B. Frankel ${ }^{\text {b }}$, Dennis A. Bazylinski ${ }^{c}$ \\ a Deparment of Geology and Geophysics, Institute for Rock Magnetism, Unicersity of Minnesota, Minneapolis, MN 55455. USA \\ ${ }^{b}$ Physics Department. California Polytechnic State Unicersity, San Luis Obispo. CA 93407. USA \\ ¿Marine Science Center. Northeastern Unicersity, Last Point, Nuhant. M.4 01908. USA
}

\section{Abstract}

We report results on the magnetic propertics of magnetites produced by magnetotactic and dissimilatory iron-reducing bacteria. Magnetotactic bacterial (MTB) strains MS1, MV1 and MV2 and dissimilatory iron-reducing bacterium strain GS-15. grown in pure cultures, were used in this study. Our results suggest that a combination of room temperature coercivity analysis and low temperature remanence measurements provides a characteristic magnetic signature for intact chains of single domain (SD) particles of magnetite from MTBs. The most useful magnetic property measurements include: (1) acquisition and demagnetization of isothermal remanent magnetization (IRM) using static, pulse and alternating fields; (2) acquisition of anhysteretic remanent magnetization (ARM); and (3) thermal dependence of low temperature $(20 \mathrm{~K})$ saturation IRM after cooling in zero field (ZFC) or in a $2.5 \mathrm{~T}$ field $(\mathrm{FC})$ from $300 \mathrm{~K}$. However, potentially the most diagnostic magnetic parameter for magnetosome chain identification in bulk sediment samples is related to the difference between low temperature zero-field and field cooled SIRMs on warming through the Verwey transition $(T \approx 100 \mathrm{~K})$. Intact chains of unoxidized magnetite magnetosomes have ratios of $\delta_{\mathrm{FC}} / \delta_{\mathrm{ZFC}}$ greater than 2, where the parameter $\delta$ is a measure of the amount of remanence lost by warming through the Verwey transition. Disruption of the chain structure or conversion of the magnetosumes to maghemite reduces the $\delta_{\mathrm{FC}} / \delta_{\mathrm{ZrC}}$ ratio to around 1 , similar to values observed for some inorganic magnetite. maghemite, greigite and GS-15 particles. Numerical simulations of $\delta_{\mathrm{FC}} / \delta_{Z F C}$ ratios for simple binary mixtures of magnetosome chains and inorganic magnetic fractions suggest that the $\delta_{\mathrm{fC}} / \delta_{\mathrm{ZFC}}$ parameter can be a sensitive indicator of biogenic magnetite in the form of intact chains of magnetite magnetosomes and can be a useful magnetic technique for identifying them in whole-sediment samples. The strength of our approach lies in the comparative ease and rapidity with which magnetic measurements can be made, compared to techniques such as electron microscopy.

\section{Introduction}

The biomineralization of magnetite $\left(\mathrm{Fe}_{3} \mathrm{O}_{4}\right)$ and greigite $\left(\mathrm{Fe}_{3} \mathrm{~S}_{4}\right)$ by a variety of microorganisms is an important source of fine-grained magnetic material that can contribute significantly to stable natural remanent magnetization (NRM) in recent and ancient sediments [1-4]. Magnetic, single domain (SD) sized particles $(<0.1 \mu \mathrm{m})$ of magnetite of possible biogenic origin have been identified in sediments from several different depositional environments of various ages including: 
(1) present day sediments from lakes, ponds, and estuaries [2,5]; (2) Holocene carbonate and hemipelagic surface sediments [6-8]; (3) Quaternary to Eocene deep-ocean sediments $[9,10]$; and (4) Late Jurassic and Cambrian limestones [2,7]. When documented, a stable primary NRM is usually associated with the occurrence of this fine-grained magnetite.

One group of magnetite-producing microorganisms, known collectively as magnetotactic bacteria (MTB), synthesize intracellular membranebounded magnetite (or greigite) particles called magnetosomes [11,12]. Various arrangements of magnetosomes within cells impart a permanent magnetic dipole moment to the cell that enables it to orient itself and migrate along the geomagnetic field towards favorable habitats [12]. Magnetotactic bacteria are a morphologically diverse and cosmopolitan group of aquatic microorganisms inhabiting freshwater and marine environments ranging from aerobic to anoxic $[11,13]$. Magnetic bacteria containing magnetite magnetosomes have also been recently identified in the $\mathrm{A}$ horizon of a waterlogged soil in Southern Bavaria [14].

The hallmarks of magnetite produced by MTBs are its narrow SD particle size distributions and distinctive crystal morphologies [e.g., 15]. For a given cell type, magnetosomes have uniform size, shape, crystal morphology and arrangement within the cell [e.g., 17,18]. This is accomplished by a process called boundary organized biomineralization (BOB), whereby magnetotactic bacteria synthesize magnetite in association with some type of biological structure or surface affording strict biological control over magnetosome design [15]. Although variations exist between species, almost all magnetosomes fall within a narrow size range of $40-120 \mathrm{~nm}$ when measured along their long axes and are within the stable $\mathrm{SD}$ size range for magnetite. Usually, 10-50 magnetosomes are arranged in linear chains within a cell with the chain axis approximately parallel to the cell's axis of motility. However, exceptions exist. For example, some magnetotactic bacteria contain hundreds of particles per cell, while others produce highly elongated (up to $300 \times 30 \mathrm{~nm}$ ) magnetosomes $[2,16]$.
A species-specific crystal morphology is another unique feature of BOB-type magnetite. High resolution transmission electron microscopy (HRTEM) of magnetosomes from different cell types show that they are single crystals (occasionally twinned) of pure stoichiometric magnetite and occur in at least three different crystal forms [15]. The simplest morphological type, found in Magnetospirillum magnetotacticum (MS-1), is cubo-octahedral. A second type, found in coccoid and vibrioid strains $\mathrm{MC}-1, \mathrm{MV}-1$, and MV-2, is an elongated hexagonal prism [17-19]. A third type, observed in some uncultured cells [15], is an elongated cubo-octahedra (bullet-shaped, teardrop and arrowhead forms). A particular species usually, but not always, produces a unique magnetosome morphology and mineral composition. Recently, a single unidentified freshwater bacterium was found to contain all three crystal types [16]. In another study, a multicellular magnetotactic organism found in brackish sulfidic habitats, produced both ferrimagnetic greigite and non-magnetic pyrite $\left(\mathrm{FeS}_{2}\right)$ particles exhibiting different crystal morphologies within the same cell [13].

Another type of magnetite-producing bacterium is the dissimilatory iron reducer Geobacter metallireducens (formerly strain GS-15) [20]. This microorganism is an obligate anaerobe and is non-magnetotactic and non-motile. GS-15 couples the oxidation of organic matter to the reduction of ferric iron, inducing, as a byproduct, the extracellular precipitation of ultrafine-grained magnetite under anaerobic conditions $[20,21]$. In laboratory culture, GS-15 can produce some 5000 times more magnetite by weight than an equivalent biomass of magnetotactic bacteria [22]. However, depending on biogeochemical conditions, GS-15 may produce siderite or vivianite instead of magnetite [21]. Magnetic iron sulfides can also be produced by sulfate-reducing bacteria such as Desulfocibrio desulfuricans [23].

In contrast to magnetotactic bacteria, dissimilatory iron-reducing microorganisms like GS-15 produce magnetite by a process called biologically induced mineralization (BIM). GS-15 modifies its local extracellular environment, creating conditions suitable for the chemical precipitation 
of magnetite and other mineral phases [21]. Because there is no strict biological control over particle synthesis, cells of strain GS-15 produce magnetite particles that are irregular in shape and have a broad grain size distribution (6-30 $\mathrm{nm}$ ) with a mean particle size of $14 \mathrm{~nm}$ [19]. The mean particle size produced by GS-15 is much smaller than the SD size of magnetosomes and is within the magnetically unstable, superparamagnetic (SPM) size range for magnetite [24]. Although GS-15 is a prodigious magnetite producer, magnetic measurements show that $96 \%$ of the particles it produces are SPM at room temperature and carry no stable remanence [25].

With few exceptions, all BOB-type magnetites have crystal morphologies that are distinct from fine-grained magnetite of inorganic origin [e.g., 15,26,27]. Morphological analysis of magnetite particles with HRTEM, therefore, provides one way of identifying biogenic magnetite (i.e., magnetosomes) in sediments [6,7]. Unlike BOB-type magnetite, particles produced by GS-15 have shape and size distributions very similar to particles of inorganic magnetite precipitated at low temperatures from aqueous solutions or during soil formation $[21,26,27]$. Hence, crystal morphology alone is not a useful criterion for identifying BIM-type magnetite.

When magnetotactic bacteria die, their magnetosomes can be deposited and preserved in sediments and acquire a depositional or post-depositional remanent magnetization $[1,3]$. The $\mathrm{SD}$ sizes of magnetosomes make them excellent recorders of the paleomagnetic field and their unusual shapes provide a means for identifying magnetosomes in sediments. However, the visual identification of magnetosomes via electron microscopy of magnetic extracts from sediments is both tedious and time consuming. An alternative approach allows whole-sediment samples to be measured using magnetic methods sensitive to the narrow SD sizes specific to biogenic systems [e.g., 10.25,28,29]. Magnetic methods have the advantage of being rapid and non-destructive but may suffer from an ambiguity in distinguishing biogenic SD particles from any other inorganic source of SD and small MD (multi-domain) particles.
Of the many types of magnetite-producing microorganisms, only a few strains have been isolated, grown in axenic culture, and made available for experimental study. In this paper, we have measured a variety of magnetic properties of magnetites from bacteria grown in pure culture. Our goal is to develop rock magnetic criteria for detecting the presence of biogenic SD particles of magnetite in sediments. Experimental results from whole-cell suspensions, freeze-dried cells, and extracted magnetosomes suggest that a combination of room temperature coercivity analysis and low temperature remanence measurements provide characteristic magnetic signatures for intact chains of SD particles of magnetite.

\section{Experimental procedures}

\subsection{Biogenic magnetites}

The four bacterial strains used in this study were MV-1, MV-2, MS-1 and GS-15. Strains MV-1 and MV-2 were isolated from water collected in New England, USA, and may actually be the same species $[17,30]$. Cells of strains MV-1 and MV-2 were grown in batch culture medium under anaerobic conditions in a diluted artificial sea water medium with nitrous oxide as the terminal electron acceptor [D. Bazylinski, unpubl. data]. Cells were harvested by centrifugation at $1000 \mathrm{~g}$ at $4^{\circ} \mathrm{C}$ and washed scveral times with 50 $\mathrm{m} M$ potassium phosphate buffer containing 18 $\mathrm{g} / 1 \mathrm{NaCl}$ at $\mathrm{pH}$ 7.2. Cells were fixed in $1 \%$ glutaraldehyde and kept in wet suspension or freeze dried after removal of the fixative. Extracted magnetosomes were obtained by cell rupture with a French pressure cell. The magnetic fraction was separated in a strong magnetic field gradient. This fraction was washed and resuspended several times in fresh buffer, treated with $1 \mathrm{M} \mathrm{NaCl}$ and washed several more times to remove adventitious protein.

Several different batches of MV-1 and MV-2 were grown. Freeze-dried samples of whole cells, designated MV1-A, MV1-B and MV1-ICIA, were grown in the presence of approximately twice as much iron as MV1-C and MV1-D. Whole-cell 
suspensions (wet cells) of MV-1 and MV-2, with letter designations $\mathrm{L}, \mathrm{M}$, and $\mathrm{H}$, were grown with a total $\mathrm{Fe}$ concentration in the growth medium of $2.4 \mu M, 12.4 \mu M$, and $27.4 \mu M$, respectively. The increase in $\mathrm{Fe}$ concentration resulted in an increase in the average number of magnetosomes per cell (from 2.4 to 7.9 ) and a decrease in the number of cells without any magnetosomes (from $18.8 \%$ to $2.9 \%$ ). Cells with different iron concentrations were purposely grown in order to study the effects of chain length on magnetic properties. However, since no systematic trends in magnetic properties with chain length were found, we will not discuss this further.

Magnetospirillum magnetotacticum (strain MS1) was obtain from the American Type Culture Collection (ATCC 31632) and grown in batch culture in a chemically defined medium [31]. Cells were harvested by centrifugation as described above, washed in a potassium phosphate buffer ( $50 \mathrm{mM}, \mathrm{pH}=7.0$ ), fixed in $2 \%$ glutaraldehyde, and kept in suspension or freeze dried after removal of the fixative. Two different batches of whole cells were grown, designated MS1-A and MS1-N.

Individual magnetite particles in cells of strains MV-1 and MV-2 are truncated hexahedral prisms with average dimensions of $53 \times 35 \times 35 \mathrm{~nm}$ and $48 \times 26 \times 26 \mathrm{~nm}$, respectively [17,19]. Particles in cells of strain MS-1 are truncated cubo-octahedra with average dimensions of $40-50 \mathrm{~nm}$ [15]. Magnetosomes in all three strains are oriented with their $\langle 111\rangle$ crystallographic and magnetic easy axes aligned along the chain axis. Chain lengths are variable, depending on growth conditions but usually contain 2-20 particles per cell. Depending on batch and culture conditions, bulk saturation magnetization $\left(J_{s}\right)$ measurements on whole cells corresponded to magnetite concentrations of $0.5-1.5 \%$ per dry cell weight.

Geobacter metallireducens (GS-15) was grown under anaerobic conditions as described previously [20]. The black precipitate produced during growth from two different batches of GS-15 was freeze dried to facilitate magnetic measurements. $J_{\mathrm{s}}$ measurements corresponded to $56 \%$ and $66 \%$ magnetite by weight in the two batches. Besides magnetite, samples also included siderite, organic debris and growth medium. The average particle size was $14 \mathrm{~nm}$ but a small fraction of particles fell within the stable SD size range at room temperature $[19,25]$.

\subsection{Inorganic magnetite, maghemite and greigite}

For comparison with our biogenic magnetites, low temperature remanence experiments were performed on several different inorganic samples of magnetite, maghemite, greigite. The magnetite and maghemite samples are synthetic powders that have been previously described in the literature and include: $(1)$ acicular maghemite $(50 \times 300$ $\mathrm{nm})$ and magnetite $(90 \times 600 \mathrm{~nm})$ from Pzifer Inc. (code no. MO2230 and MO4232) [32]; (2) two euhedral, sized magnetite samples with mean particle dimensions of $25 \mathrm{~nm}$ and $1000 \mathrm{~nm}$ from Wright Industries (code no. 4000 and 3006) [33]; and (3) euhedral magnetite with narrow particle size distributions, with mean dimensions of 37 $\mathrm{nm}, 76 \mathrm{~nm}, 100 \mathrm{~nm}$ and $210 \mathrm{~nm}[34,35]$. Before measurement, the synthetic magnetite powders were reduced back to nearly stoichiometric magnetite by heating samples in a $4: 1$ mixture of $\mathrm{CO}_{2}: \mathrm{CO}$ at $395^{\circ} \mathrm{C}$ for $72-146 \mathrm{~h}$. $J_{\mathrm{s}}$ values at room temperature after thermal treatment ranged between 85 and $90 \mathrm{Am}^{2} / \mathrm{kg}$, indicating almost complete conversion to pure magnetitc. The greigite sample is a magnetic extract from middle Miocene claystones of the Cypris Series, Sokolov Brown Coal District, Czechoslovakia [36]. The purity of the extract and the grain size of the greigite is unknown, but hysteresis parameters suggest PSD behavior $\left(J_{\mathrm{s}}=30.3 \mathrm{Am}^{2} / \mathrm{kg}, \mu_{0} H_{\mathrm{c}}=24.4 \mathrm{mT}\right.$, $J_{\mathrm{r}} / J_{\mathrm{s}}=0.252$, and $\left.H_{\mathrm{r}} / H_{\mathrm{c}}=2.05\right)$.

\subsection{Magnetic measurements}

Biogenic samples were prepared for magnetic measurement by either: (1) packing $30-80 \mathrm{mg}$ of freeze-dried cells in small aluminum foil holders; (2) mixing $250 \mu \mathrm{l}$ of whole-cell suspension with $\mathrm{CaF}_{2}$; or (3) dispersing $1 \mathrm{wt} \%$ of extracted magnetosomes or magnetite from GS-15 in a $\mathrm{CaF}_{2}$ matrix. The synthetic samples were prepared by dispersing $2 \mathrm{wt} \%$ of the powders in $\mathrm{CaF}_{2}$ matrix. 
The extracted greigite powder was measured undiluted.

Isothermal remanent magnetization (IRM) and anhysteretic remanent magnetization (ARM) were measured using a 2-G SQUID rock magnetometer. Previously demagnetized samples were given a stepwise IRM up to $0.5 \mathrm{~T}$ in a direct field (DF) using either a static field produced by an electromagnet, or a short-duration pulse field $(\approx 4 \mathrm{msec}$ duration) produced by an impulse magnetizer. Stepwise demagnetization of saturation IRM (SIRM) was determined using reversed DF (static or pulse) and alternating field (AF) demagnetization methods. IRM curves were normalized to the maximum SIRM for each sample. Reversed-field demagnetization curves were rescaled as $\frac{1}{2}(1+\operatorname{IRM}(-H) / \mathrm{SIRM})$ to simplify comparison with AF results [37]. Median remanent coercivities correspond to the $\mathrm{DF}$ or $\mathrm{AF}$ where the normalized remanence is 0.5 . Magnetic interactions were characterized by the Wohlfarth-Cisowski test, which compares IRM acquisition and demagnetization behavior $[38,39]$. When there are no interactions between SD particles or no internal demagnetizing effects within MD particles, the remanent coercivity spectra determined from acquisition and demagnetization remanence curves should be identical and cross at a normalized intensity of 0.5 , when plotted together as a function of the applied field [37-39]. ARM was produced by a combination of small stcady fields $(10-200 \mu \mathrm{T})$ and a decaying AF with an initial peak value of $100 \mathrm{mT}$. All magnetization and demagnetization measurements were made along a single axis. Hall-effect sensors were used to measure static and pulse fields and each probe was calibrated with a standard reference magnet $(0.2 \mathrm{~T} \pm 0.5 \%)$. The pulse field was measured with a Hall-effect probe and a storage oscilloscope.

Hysteresis loops were measured using a vibrating sample magnetometer in fields up to $1.5 \mathrm{~T}$. The temperature dependence of SIRM between $20 \mathrm{~K}$ and $300 \mathrm{~K}$ was measured with a Quantum Design SQUID susceptometer. Samples were given an SIRM in a field of $2.5 \mathrm{~T}$ at $20 \mathrm{~K}$, and then measured in approximately zero field (see below ) at $5 \mathrm{~K}$ intervals up to $300 \mathrm{~K}$. Before SIRM

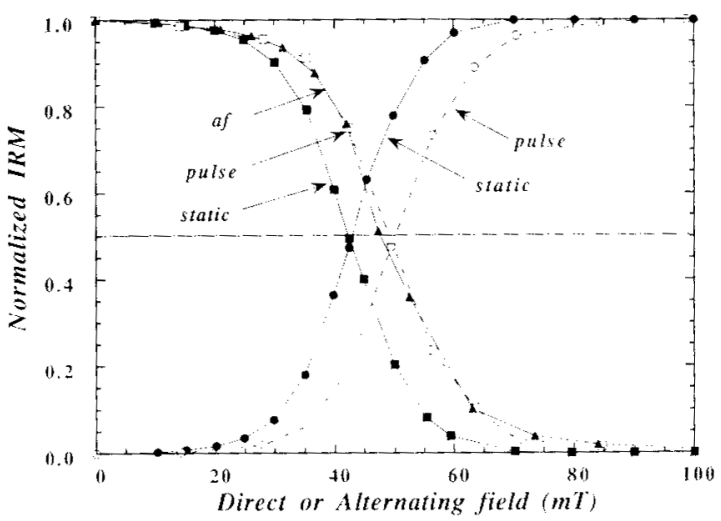

Fig. 1. Normalized IRM acquisition and demagnetization for a whole cell sample (MV1-A). Dot = static field acquisition solid square = static DF demagnetization circle $=$ pulse field acquisition; outlined square = pulse DF demagnetization: solid triangle $=\mathrm{AF}$ demagnetization .

acquisition at $20 \mathrm{~K}$, samples were cooled from $300 \mathrm{~K}$, either by zero field cooling ( $\mathrm{ZFC}$ ) or field cooling (FC) in $2.5 \mathrm{~T}$. For SIRM experiments using wet cells, $240 \mu \mathrm{l}$ of suspended cells were placed in a small, airtight plastic holder and frozen in a zero field at $240 \mathrm{~K}$. The residual field of the superconducting solenoid after a magnet reset from $2.5 \mathrm{~T}$ is approximately $200-300 \mu \mathrm{T}$.

\section{Room temperature results}

\subsection{Remanent coercility spectra: intact chains of} magnetosomes

Coercivity spectra were determined from IRM curves using a combination of: (1) static field acculuisition and DF demagnetization; (2) pulse field acquisition and DF demagnetization; and (3) AF demagnetization. An example of coercivity spectra obtained from these measurements for freeze-dried cells is shown in Fig. 1. For each pair of static and pulse field spectra, acquisition and demagnetization are nearly symmetrical, with a crossover point $R_{\mathrm{dt}} \approx 0.5$. where the subscript $d f$ denotes an $R$ value determined from DF magnetization curves. All wet and freeze-dried cells exhibited this type of response, which is the theoretically predicted behavior for an ensemble of 
non-interacting SD particles [38]. For wet and freeze-dried cells, chain--chain interactions are minimized because the surrounding cell membranes keep chains separated [28]. Although magnetosomes along a chain are close together, the standard Wohlfarth-Cisowski test for interactions is apparently insensitive to positive interactions among magnetosomes along individual linear chains.

More significant, however, is the shift in the coercivity spectra between static and pulse field methods. This shift is due to differences in thermally assisted moment switching in fields with different sweep rates and is a purely time-dependent effect. Since, according to Néel's SD theory, coercivity is a function of time, as well as temperature and particle volume, various estimates of
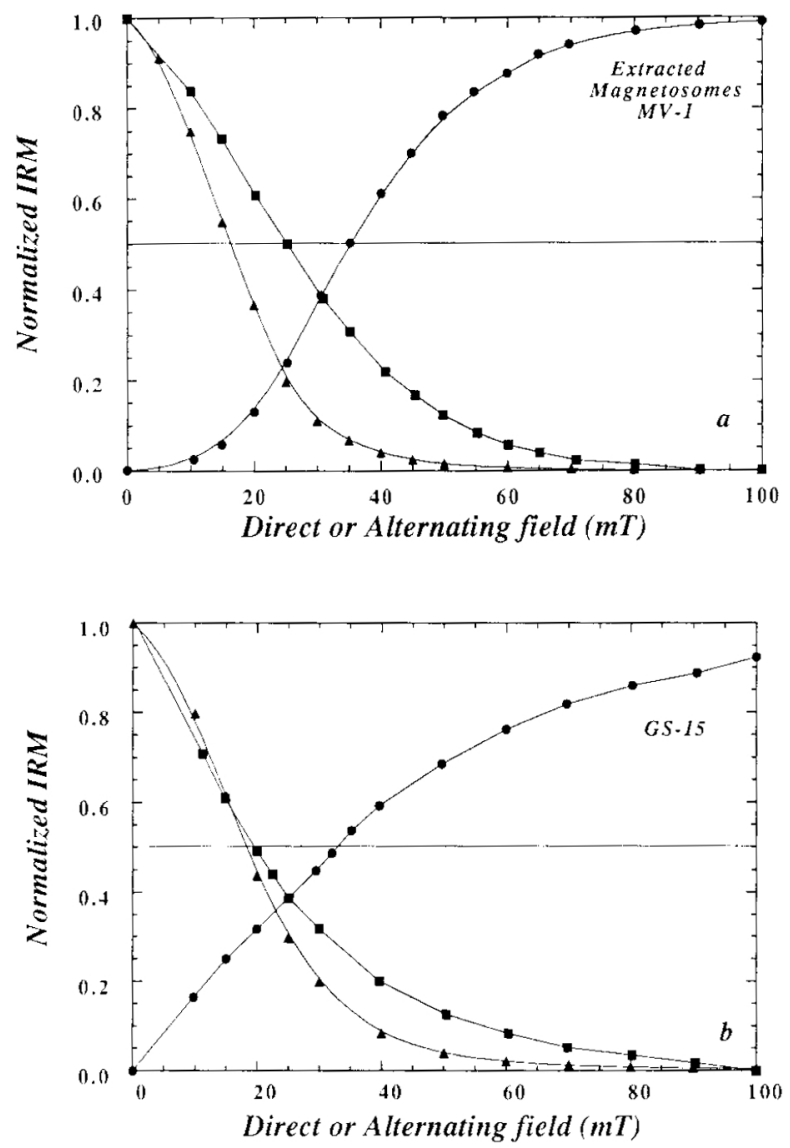

Fig. 2. Normalized IRM static field acquisition (dot), DF demagnetization (solid square) and AF demagnetization (solid triangle) for (a) extracted magnetosomes and (b) GS-15. coercivity will increase with increasing frequency or sweep rate of the applied field [40]. Because there is less time for magnetosomes to respond to high frequency pulse treatments $\left(t \approx 10^{-3} \mathrm{~s}\right)$ higher pulse fields are required to achieve the same remagnetization state obtained with static fields $\left(t \approx 10^{2} \mathrm{~s}\right)$. Hence, pulse field spectra are shifted toward high fields relative to static field spectra.

When AF demagnetization is used instead of DF demagnetization in the Wohlfarth-Cisowski test, there is also an apparent shift in the $R$ value depending on whether static or pulse fields are used for acquisition (Fig. 1). For wet and freezedried cells, $R_{\mathrm{af}} \approx 0.5$ for pulse fields but $R_{\mathrm{af}}>0.5$ for static fields. The subscript af denotes an $R$ value determined from AF demagnetization curves. The pulse field results show nearly perfect symmetry between the DF and AF curves as expected for non-interacting SD particles because the pulse $(\approx 250 \mathrm{~Hz})$ and $\mathrm{AF}(400 \mathrm{~Hz})$ have similar field switching frequencies. In the example shown in Fig. 1, the median remanent coercivity determined from pulse field measurements is $6.3 \mathrm{mT}$ greater than the corresponding static field result.

In contrast, the paring of static and AF curves gives $R_{\mathrm{af}}=0.52-0.6$ for whole-cell samples of intact chains, except for sample MS1-N which had $R_{\text {af }}=R_{\text {df }}=0.47$. Previously, $R_{\text {af }}$ values zreater than 0.5 were mistakenly attributed to positive, short range magnetostatic interactions [28]. Nevertheless, a $R_{\text {af }}$ value greater than 0.5 is a distinctive response of intact chains of magnetosomes within our series of samples. The uniform SD particle sizes and insignificant chainchain interactions allow this subtle time-dependent effect to be observed.

\subsection{Remanent coercivity spectra: extracted magne- tosomes and BIM-type magnetite}

The IRM coercivity spectra for dispersed samples of extracted magnetosomes and GS-15 magnetite are plotted in Fig. 2 and show the characteristic asymmetric behavior $\left(R_{\mathrm{af}}<0.5\right)$ produced by negative magnetostatic interactions $[37,39]$. A mean negative interaction field produced by par- 
ticle agglomeration shifts the demagnetization spectra toward lower fields relative to the acquisition spectra and shifts $R_{\text {af }}$ to a value below 0.5 . This is opposite to the time-dependent effect observed with intact chains, which shifts $R_{\text {af }}$ to a value above 0.5 . Although interaction effects are dominant. time-dependent behavior is still observed. Whereas the $R_{\text {df }}$ values are nearly identical for extracted magnetosomes and GS-15, their $R_{\text {af }}$ values are not. For instance, GS-15 exhibits a pronounced time-dependent behavior because of a significant fraction of particles near the SPMSD boundary. As a consequence, GS-15 exhibits the largest difference between pulse and static field determinations of median remanent coercivity $(11 \mathrm{mT})$ of any of our samples.

The Wohlfarth-Cisowski test with $R_{\text {af }}<0.5$ is typical of inorganic synthetic and natural samples of $\mathrm{SD}$ and $\mathrm{MD}$ size $[37,39,41]$ and is, therefore, not particularly diagnostic of BIM-type, or isolated magnetosomes that may clump together in sediments after deposition. Of course, the concentration and degree of interaction of biogenic magnetites may be considerably less under natural conditions.

\subsection{Anhysteretic remanent magnetization}

Besides differences in the Wohlfarth-Cisowski test, there is a marked contrast in the efficiency of weak-field ARM acquisition for the various types of biogenic magnetites [28]. ARM induction curves for wet cells, freeze-dried cells, extracted magnetosomes and GS-15 are shown in Fig. 3. The shape of the ARM induction curve correlates with the expected degree of interactions in our samples. GS-15 and extracted magnetosomes show slow linear increases in ARM, reaching only approximately $15 \%$ of saturation by $1.5 \mathrm{mT}$. In contrast, samples of whole cells with intact chains show a rapid initial increase in ARM acquisition and attainment of $70-90 \%$ saturation by $1.5 \mathrm{mT}$. Unlike the $R$ parameters, weak-field ARM acquisition is sensitive to differences in magnetic interactions between wet and freeze-dried cells. Nearest-neighbor chain distances are probably shorter on average in freeze-dried cells than in wet cells, due to the collapse of the cell body

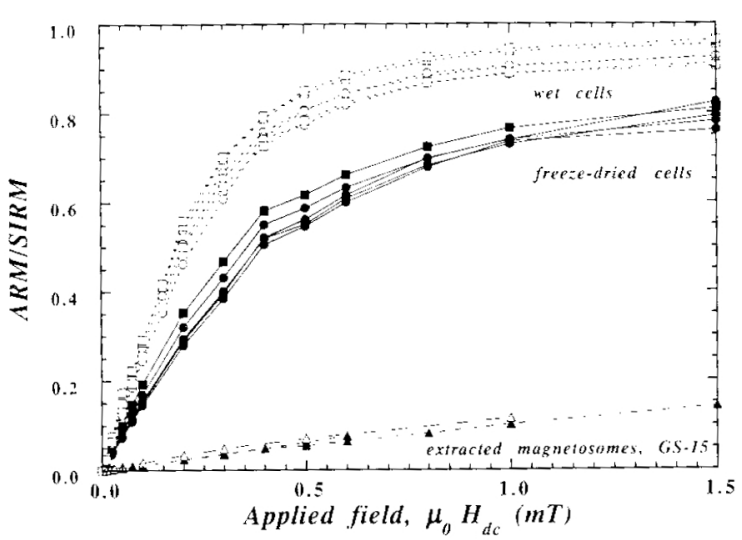

Fig. 3. Normalized ARM as a function of applied DC field for wet cells (dotted lines), freeze-dried cells (solid lines), extracted magnetosomes (short dashed line), and GS-15 (long dashed line). ARM is normalized by the sample's SIRM. Biogenic samples include: MV1 (dots and circles), MV2 (outlined square), MS1 (solid square), extracted MV1 and MSI magnetosomes (solid triangle), and GS-15 (outlined triangle).

after freeze drying. This results in an increase in interaction fields and a diminished ARM capacity. The ARM/SIRM ratio at $\mu_{0} H=0.1 \mathrm{mT}$ will serve to quantify the ARM results.

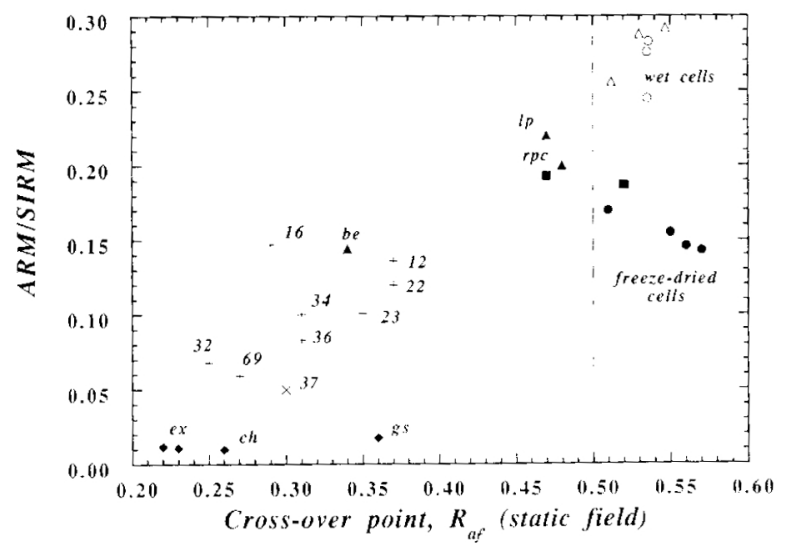

Fig. 4. ARM/SIRM versus cross-over point $R_{\text {aff }}$ for selected fine-grained biogenic and inorganic magnetite/maghemite samples. ARM intensity is for a steady field of $0.1 \mathrm{mT}$. Biogenic samples: circle = MV1 (wet cells); outined triangle = MV2 (wet cells); dot = MV1 (freeze-dried cells); solid square $=$ MS1 (freeze-dried cells); $g s=$ GS-15; ex = extracted magnetosomes: $c h=$ chiton teeth [39]. Inorganic synthetic samples: $+=$ synthetic magnetites (number by symbol is mean particle size in nanometers) [41]; $x=$ synthetic magnetite $(37$ nm) [39]. Inorganic natural samples (outlined triangle): $b e=$ Exmoor Brown Earth [27]; $l p=$ Lambertville plagioclase [39]; $r p c=$ remagnetized paleozoic carbonate [48]. 


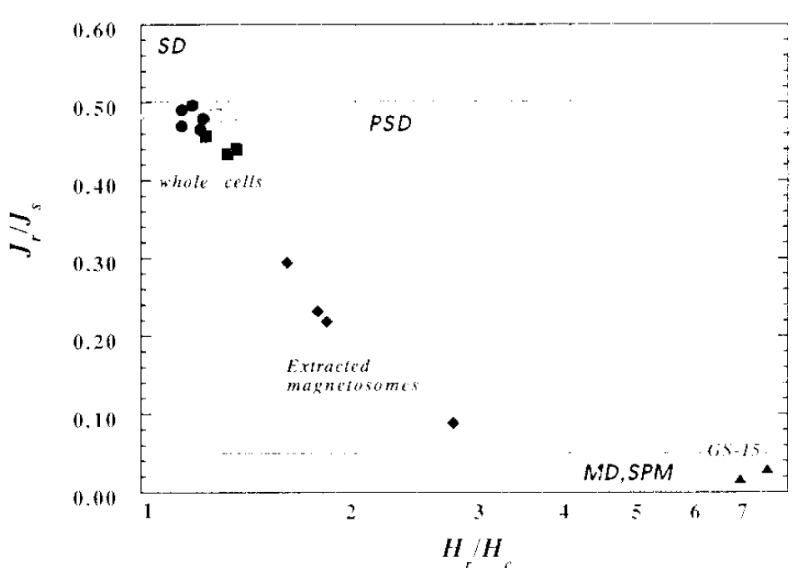

Fig. 5. A semi-log plot of hysteresis ratios $J_{\mathrm{r}} / J_{\mathrm{s}}$ and $H_{\mathrm{r}} / H_{\text {a }}$ for biogenic samples. $J_{r}=$ saturation remanence. $J_{\mathrm{s}}=$ saturation magnetization. $H_{r}=$ coercivity of remanence and $H_{\mathrm{c}}=$ coercivity. Domain state boundatries represent typical parameter ranges for single domain $(S D)$, pseudo-single domain (PSD). multidomain $(M D)$ and superparamagnetic $(S P M)$ behavior. Dot = MV1 (freeze dried cells); solid square $=$ MSl (frecze- dried cells): outlined square $=$ MV1. MV2 (wet cells): solid diamond = extracted magnetosomes; solid triangle $=$ GS-15.

The ARM/SIRM ratio versus $R_{\text {at }}$ parameter for several different types of fine-grained inorganic and biogenic magnetites are plotted in Fig. 4. It is evident from this figure that the ARM/ SIRM ratio correlates well with $R_{\text {at }}$ because interactions affect both parameters, either through dipolar interaction fields between SD particles or internal demagnetizing fields within MD particles [37,39]. Higher values of ARM/SIRM and $R_{\text {all }}$ indicate a decrease in the degree of interactions. Also evident from the data in Fig. 4 is the potential diagnostic value of concurrent high values of ARM $/ \operatorname{SIRM}(>0.10)$ and $R_{\text {at }}>0.5$ as a characteristic magnetic signature for intact chains of magnetosomes.

\subsection{Hysteresis parameters}

Standard hysteresis parameters $\left(J_{\mathrm{r}} / J_{\mathrm{s}}\right.$ and $H_{\mathrm{r}} / H_{\mathrm{c}}$ ) for the biogenic magnetites are shown in Fig. 5. The response of wet and freeze-dried cells is typical of SD particles but is not, by itself. particularly diagnostic for biogenic magnetite. The BIM-type magnetite produced by GS-15 consists mostly of SPM-sized particles with hysteresis pa- rameters that plot within the MD/SPM region of the diagram. Based on hysteresis parameters alone, an SPM signal from GS-15 could be confused with a coarse grained. MD response.

Extracted magnetosomes have lower $J_{\mathrm{r}} / J_{\mathrm{s}}$ and higher $H_{\mathrm{r}} / H_{\mathrm{c}}$ ratios than their intact counter. parts. The reason for this is unclear. It may, again, be related to interactions; although other investigators note only a slight concentration de. pendence of hysteresis properties [e.g., 34]. Another possible explanation is that a small fraction of SPM particles of maghemite have formed by the surface oxidation of the bare magnetosomes under ambient conditions. The non-uniform oxidation of the magnetosome mily cause the surface to crack, resulting in clusters of SPM particles of maghemite surrounding a core of magnetite, similar to effects observed in fine particles of synthetic magnetite [35] and corroded magnetofossils from deep-sea sediments [42]. An alternative hypothesis is that the SPM particles are immature magnetosomes formed during the early stages of crystal growth [15]. The SPM behavior of the immature magnetosomes is suppressed when in chains but becomes apparent once the particles are extracted. The hysteresis data for extracted magnetosomes appear to lic along a mixing line between the SD response of whole cells and the SPM response of GS-15, consistent with the hypothesis that these samples are mixtures of SPM and SD particle sizes. Further support for this hypothesis comes from low temperature remanence measurements discussed in section 4 .

\section{Low temperature results}

\subsection{SIRM at $20 \mathrm{~K}$}

The thermal decay of SIRM given at $20 \mathrm{~K}$ after field cooling in $2.5 \mathrm{~T}$ from $300 \mathrm{~K}$ for whole cells, extracted magnetosomes and GS-15 is shown in Fig. 6. Whole-cell samples of MV-1, MV-2, and MS-1 show a sharp drop in SIRM intensity between 100 and $110 \mathrm{~K}$. Freeze-dried cells exhibit a slightly faster decay of SIRM below $100 \mathrm{~K}$ than frozen wet cells. The remanence transition $\left(T_{\mathrm{v}}\right)$ is an expression of the cubic to monoclinic crystallo- 
graphic phase transition in magnetite at $110-120$ k. known as the Verwey transition [e.g., 43]. Unlike whole cells of magnetotactic bacteria, magnetite produced by GS-15 shows an initially apid decrease in intensity below $60 \mathrm{~K}$ and then a nore gradual decrease to $300 \mathrm{~K}$. There is no vidence of a remanence transition near $100 \mathrm{~K}$. This behavior is typical of superparamagnetism and consistent with the presence of SPM particles in GS-15 [19,25]. The shape of the GS-15 curve is due to the distribution of blocking temperatures related to particle size, resulting in the progressive unblocking of magnetization as the temperature is increased. GS-15 produces such a small fraction of grains that are within the stable SD size range at $300 \mathrm{~K}$ that their remanence hehavior at $100 \mathrm{~K}$ is swamped by the SPM response.

The thermial decay of SIRM for extracted magnetosomes exhibits an initially rapid decrease in SIRM below $50 \mathrm{~K}$ and a broad remanence transition below $100 \mathrm{~K}$ (Fig. 6). This type of thermal behavior is intermediate between the sharp transition in the whole cells and the SPM behavior of $\mathrm{GS-15}$. It is characteristic of finegrained magnetites that have been partially oxidized to SPM maghemite [35]. The low temperature results are consistent with our interpretation

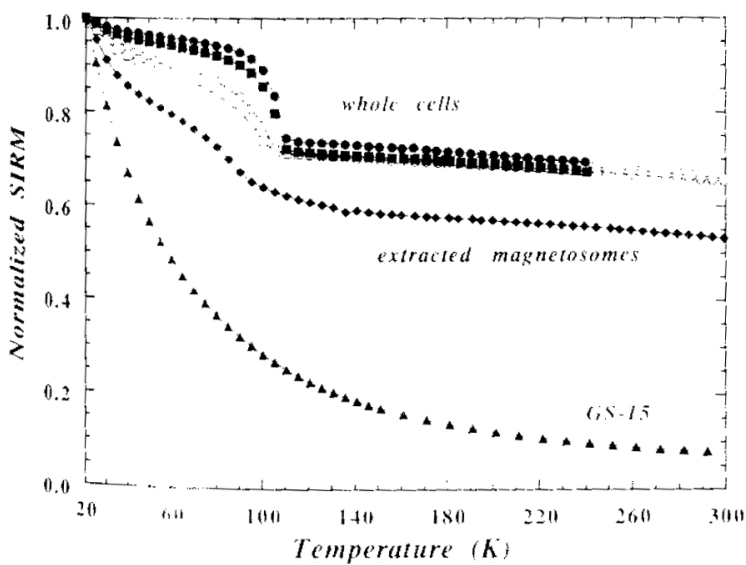

Fig. 6. Thermat demagnetization of field cooled (FC) SIRM for biogenic samples. SIRM was given in $2.5 \mathrm{~T}$ at $20 \mathrm{~K}$ after samples were conled through the Verwey transition in $2.5 \mathrm{~T}$. Dot $=$ MV1 (wet cells): solid square $=$ MV2 (wet cells): circle $=$ MV1 (freez-dried cells); outlined square = MS1 (treezedried cells): solid diamond = extracted magnetosomes $(\mathrm{MVL})$; solid triangle $=(\mathrm{S} S-15$.

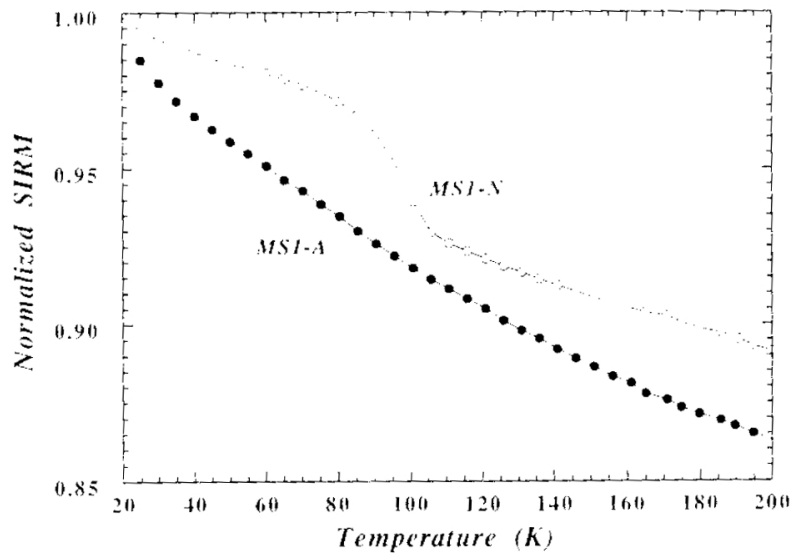

Fig. 7. Thermal demagnetization of zero field cooled (ZFC) SIRM for two samples of MS-1. SIRM was given in $2.5 \mathrm{~T}$ at $20 \mathrm{~K}$ atter samples were cooked through the Verwey transition in zero field. MS1-A has oxidized to maghemite. supprossing the remanence transition near $100 \mathrm{k}$.

of the room temperature hysteresis data as resulting from mixtures of SD and SPM particles caused by maghemitization (Fig. 5).

An example of the effects of maghemitization on the thermal dependence of SIRM for intact chains of magnetosomes is shown in Fig. 7. Two different batches of freeze-dried cells of MS-1 were cooled from $300 \mathrm{~K}$ in zero field before SIRM acquisition at $20 \mathrm{~K}$. As is evident from Fig. 7. the magnetite transition expected for these samples is present in MS1-N but suppressed in MS1-A. The decay of remanence with temperature in MS1-A is gradual, with just $14 \%$ of the initial SIRM lost by $200 \mathrm{~K}$. However. extracted magnetosomes and GS-15 lose between $40 \%$ and $60 \%$ of their initial SIRM by $200 \mathrm{~K}$, suggesting that there is a negligible fraction of SPM particles in MSI-A. This is supported further by the room temperature hysteresis parameters for MS1-A. which indicate only stable $\mathrm{SD}$ behavior $\left(J_{\mathrm{r}} / J_{\mathrm{V}}=\right.$ 0.43, $H_{\mathrm{r}} / H_{\mathrm{c}}=1.32$ ). Either the magnetosomes in MS1-A were converted to maghemite without any surface cracking and formation of SPM particles, or the SPM behavior is somehow suppressed due to cooperative interactions along the chain. MS1$A$ is the only sample of freeze-dried cells in our collection which appears to have oxidized to maghemite. 


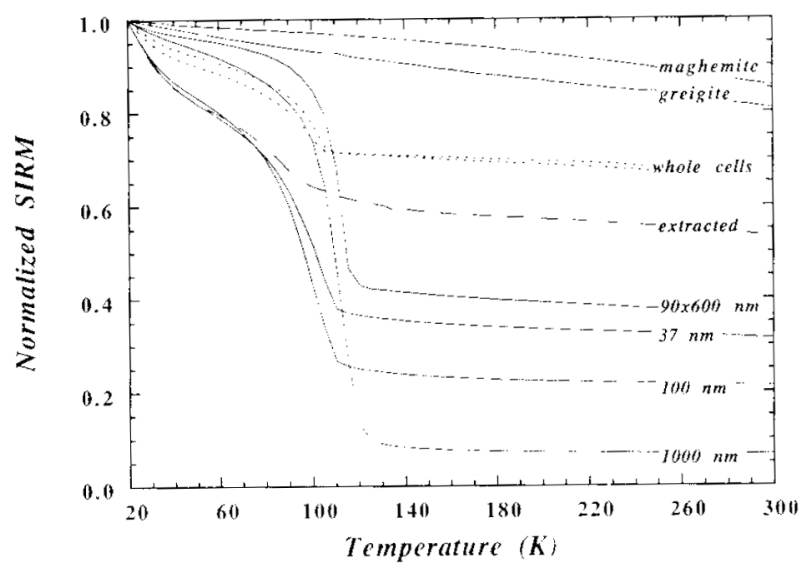

Fig. 8. Thermal demagnetization of field cooled (FC) SIRM for biogenic and inorganic samples. SIRM was given in $2.5 \mathrm{~T}$ at $20 \mathrm{~K}$ after samples were cooled through the Verwey transition in $2.5 \mathrm{~T}$. Numbers on curves are mean particle sizes for synthetic magnetites. Solid lines = inorganic samples; dotted line $=$ MV1 and MSI: dashed line = extracted magnetosomes (MV1).

\subsection{Low temperature SIRM of inorganic mag- netite, maghemite, and greigite}

The thermal dependence of SIRM for acicular maghemite $(50 \times 300 \mathrm{~nm})$ and magnetite $(90 \times 60$ $\mathrm{nm})$, euhedral magnetite $(37 \mathrm{~nm}, 100 \mathrm{~nm}$ and $1000 \mathrm{~nm}$ ), and greigite (unknown grain size) are shown in Fig. 8, along with some of our results from MTBs. Maghemite and greigite show only a gradual decrease in SIRM with temperature between $20 \mathrm{~K}$ and $300 \mathrm{~K}$, consistent with the expected theoretical decay of saturation magnetization. There is no remanence transition in maghemite because it does not undergo a phase change at low temperatures [e.g., 43]. Our greigite results appear to be the first reported low temperature remanence measurements for a natural sample of this mineral phase. This particular greigite does not exhibit a Verwey-type remanence transition below $300 \mathrm{~K}$, nor does it show the $30 \mathrm{~K}$ transition seen in pyrrhotite, agreeing with magnetic and Mössbauer measurements reported for synthetic ultrafine-grained samples of greigite [44]. Although we do not have any samples of BOB- or BIM-type greigite for comparison, our preliminary results suggest that low temperature remanence measurements will not be a useful method for identifying biogenic or inor. ganic greigite in natural samples.

All inorganic magnetites above the SPM threshold size exhibit a remanence transition near 100-110 K [35], similar to the behavior observed in the magnetotactic bacteria. Therefore, the remanence transition observed in whole cells and extracted magnetosomes is not unique to $\mathrm{BOB}$. type magnetite but is probably typical of all types of stoichiometric magnetites larger than approximately $20 \mathrm{~nm}$. However, the amount of remanence lost at $T_{v}$ is significantly less for whole cells than for dispersions of comparably sized synthetic magnetite (37 $\mathrm{nm}$ and $100 \mathrm{~nm})$. To quantify this behavior, we define the parameter $\delta$ as a measure of the amount of remanence lost by warming through $T_{\mathrm{v}}$ :

$\delta=\frac{J_{\mathrm{irm}}(80)-J_{\mathrm{irm}}(150)}{J_{\mathrm{irm}}(80)}$

where $J_{\text {irm }}$ refers to the initial SIRM remaining at 80 or $150 \mathrm{~K}$. As shown in the next section, there is a marked difference in $\delta$ values between zero field and field cooled SIRMs for whole cells and synthetic magnetites.

\subsection{Zero field cooled (ZFC) and field cooled (FC) SIRM}

The thermal dependence of SIRM given at 20 $\mathrm{K}$ after whole-cell samples are cooled through the

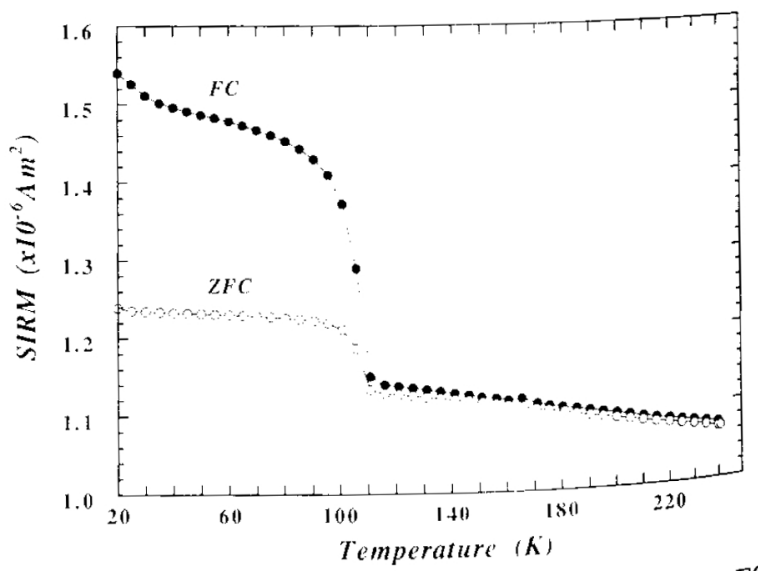

Fig. 9. A comparison of the thermal demagnetization of $F C$ and ZFC SIRMs for MV1-H. Results are typical of whole-cell samples MV1, MV2 and MS1. 
Verwey transition in either zero field ( $\mathrm{ZFC}$ ) or in a strong field of $2.5 \mathrm{~T}(\mathrm{FC})$ is strikingly different. A typical example is shown in Fig. 9 for MV1-H. For all the whole-cell samples except MS1-A, the initial SIRM intensity at $20 \mathrm{~K}$ is approximately $25-30 \%$ greater and the remanence transition at $100 \mathrm{~K}$ is more conspicuous $\left(\delta_{\mathrm{FC}}>\delta_{\mathrm{ZFC}}\right)$ after FC than ZFC treatments. Yet, whatever differences exist between FC and ZFC SIRMs below $T_{v}$ disappear once the sample is warmed through $T_{\mathrm{v}}$.

To explain our $\mathrm{FC}$ and $\mathrm{ZFC}$ results, recall that individual cells consist of a single chain of SD magnetosomes, with each magnetosome aligned with one of its $\langle 111\rangle$ magnetic easy axes along the chain direction. The chain structure effectively removes the equivalence among the different $\langle 111\rangle$ easy directions and produces a uniaxial anisotropy along one particular $\langle 111\rangle$ direction. At room temperature, whole-cell samples have $J_{\mathrm{r}} / J_{\mathrm{S}} \approx 0.5$, indicating a random distribution of uniaxial "SD chains". Associated with the Verwey transition is a magnetic isotropic point where the magnetocrystalline anisotropy constant $\left(K_{1}\right)$ equals zero and the easy directions of magnetization change their orientation from [111] above $T_{v}$ to $[100]$ below $T_{\mathrm{v}}$ [e.g., 43]. Magnetite is monoclinic below the Verwey transition, with a uniaxial magnetic easy axis parallel to the monoclinic $c$ axis, coinciding with one particular [100] direction of the high-temperature cubic spinel phase [e.g., 45]. When whole cells are cooled through $T_{v}$ in zero field, the new $c$ axes are randomly selected from one of the three $\langle 100\rangle$ directions, resulting in a new random distribution of easy axes. How the $c$ axes are oriented along the chain or between magnetosomes is not known; however, $J_{\mathrm{r}} / J$, values for bulk samples are still approximately 0.5 , indicating a random distribution of uniaxial "SD chains".

Upon cooling through $T_{\mathrm{v}}$ in a strong magnetic field, the $\langle 100\rangle$ direction most nearly parallel to the field direction now becomes the new $c$ axis [45]. This induces a partial alignment of new magnetic casy axes in the direction of the cooling field, producing higher SIRM intensities below $T_{\mathrm{v}}$, an increase in $J_{\mathrm{r}} / J_{\mathrm{s}}$ to $0.60-0.65$ at $20 \mathrm{~K}$, and $\delta_{\mathrm{FC}} / \delta_{\mathrm{ZIC}}>2$. Warming back through the Verwey transition temperature, the $\mathrm{ZFC}$ and $\mathrm{FC}$ curves

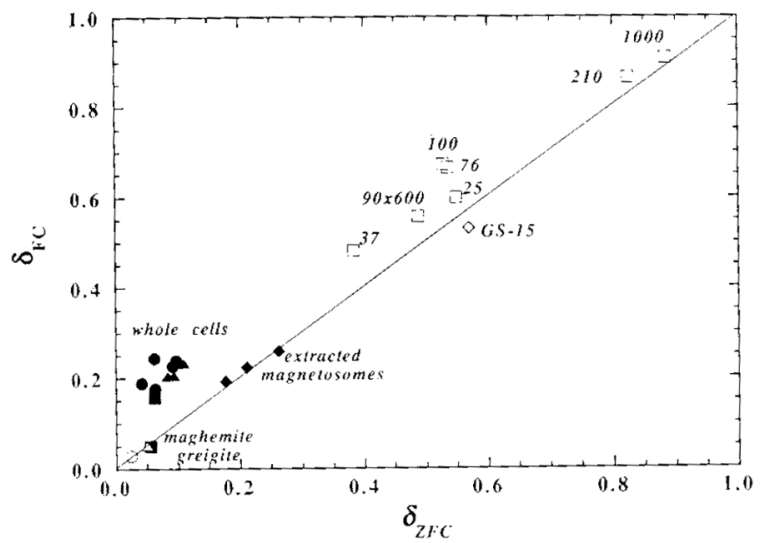

Fig. 10. A plot of $\delta_{\mathrm{FC}}$ versus $\delta_{\mathrm{ZFC}}$ for biogenic and inorganic samples. The $\delta$ parameter is defined in Eq. (1) and is a measure of the amount of remanence lost on warming through the Verwey transition. Inorganic samples: outlined square $=$ synthetic magnetite (number by symbol is mean particle size in nanometers); circle $=$ maghemite: outlined triangle $=$ greigite. Biogenic samples: $\mathrm{dot}=\mathrm{MVl}$; solid square $=\mathrm{MSl}$ : solid triangle $=\mathrm{MV} 2$; solid diamond $=$ extracted magnetosomes; outlined diamond = GS-15. Solid line has a slope of 1.0 .

merge as the direction of magnetization switches back to the original $\langle 111\rangle$ easy axis along the chain direction. The direction of remanent magnetization below $T_{\mathrm{v}}$ is not necessarily parallel to $\langle 100\rangle$ but most likely takes an equilibrium position in the plane defined by $\langle 111\rangle$ and $\langle 100\rangle$. determined by the relative magnitudes of chain (shape) and crystalline uniaxial anisotropies.

In marked contrast to the whole-cell results, the SIRM behavior of extracted magnetosomes and inorganic SD and MD magnetites differs little for FC or ZFC SIRMs. This is evident in Fig. 10, which shows $F C$ and $\mathrm{ZFC}$ results for biogenic and inorganic samples in terms of the $\delta_{F C}$ and $\delta_{Z F C}$ parameters. There are two different mechanisms that contribute to a loss in remanence on passing through $T_{v}$, depending on whether grains have domain walls or not. In MD grains, as $K_{1}$ becomes zero at $T_{v}$, domain walls become unpinned and lead to the almost complete demagnetization of the initial low temperature SIRM [e.g., 46]. Demagnetizing fields in individual MD grains may exert more of a local influence in determining the direction of the low temperature easy axes than the external field. 
This, coupled with a distribution of particle sizes, domain states, or both, either masks or completely eliminates any difference between ZFC and FC SIRMs.

In SD grains, on the other hand, remanence changes at $T_{\mathrm{v}}$ because magnetization rotates to a new equilibrium position determined by the relative contributions of shape and crystalline anisotropy as the easy axis switches direction from $\langle 111\rangle$ to $\langle 100\rangle$. However, it is unclear why there is not a similar difference between ZFC and FC SIRMs in our two inorganic SD samples $(37 \mathrm{~nm}, 90 \times 600 \mathrm{~nm})$ as that observed in the intact magnetosomes. The usual suspects, such as a distribution in particle sizes and shapes or dipolar interactions, may explain this discrepancy but are not entirely satisfactory explanations.

Before discussing the diagnostic potential of these data for identifying intact chains of magnetosomes in natural samples, there are several key features worth noting in Fig. 10. All the synthetic magnetites have $\delta$ values greater than 0.4 and ratios of $\delta_{\mathrm{FC}} / \delta_{\mathrm{ZFC}}$ ranging between 1.0 and 1.3 . In addition, $\delta$ increases with particle size from SD to small MD sizes [35]. Maghemite and greigite, which have no low temperature remanence transitions, have very low $\delta$ values of 0.02 and 0.05 , respectively. Low $\delta$ values correspond to a gradual decrease in SIRM, presumably reflecting slight decreases in $J_{(}(T)$ between $80 \mathrm{~K}$ and $150 \mathrm{~K}$. GS-15, which also has no remanence transition, has a high value of $\delta$ simply because of its large SPM fraction, which produces a significant amount of unblocking of SIRM between $80 \mathrm{~K}$ and $150 \mathrm{~K}$. Extracted magnetosomes have $\delta$ values that plot along the line $\delta_{\mathrm{FC}}=\delta_{\text {ZFC }}$ and link the values between stoichiometric synthetic magnetite and maghemite. These $\delta$ values could indicate a continuation of the grain size trend observed for the synthetic magnetites. On the other hand, the trend of extracted magnetosomes suggests mixtures of magnetite and maghemite and supports our previous assertions that the bare magnetosomes have become partially oxidized to mixtures of magnetite and SPM maghemite. Finally, MS1-A, which we believe has converted completely to maghemite has $\delta_{\mathrm{TFC}}$ and $\delta_{\mathrm{FC}}$ values close to our maghemite sample.

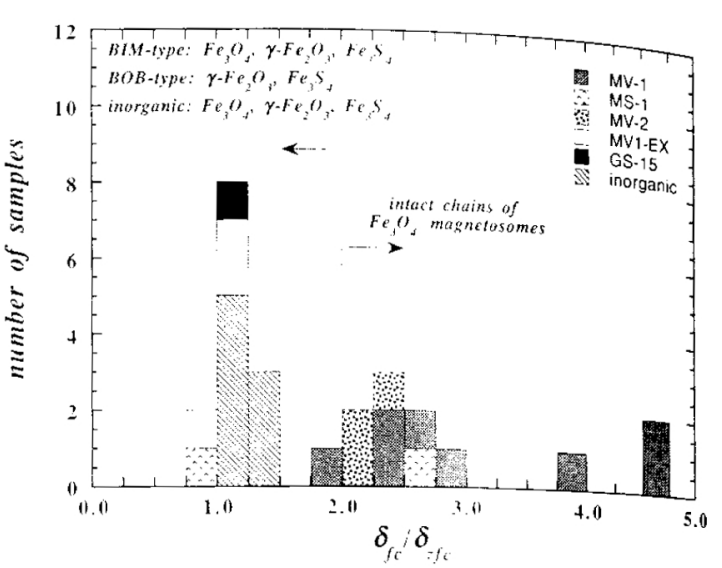

Fig. 11. Histogram of $\delta_{\mathrm{FC}} / \delta_{\mathrm{ZFC}}$ ratios for biogenic and inorganic samples. A ratio greater than 2.0 is characteristic of intact chains of magnetite magnetosomes.

The best way to summarize our low temperature SIRM results and to show its potential diag. nostic usefulness is to plot $\delta_{\mathrm{FC}} / \delta_{\mathrm{ZFC}}$ ratios as a histogram (Fig. 11). This figure clearly shows that intact chains of unoxidized magnetosomes have the largest ratios of $\delta_{\mathrm{FC}} / \delta_{\mathrm{ZFC}}(>2)$ in our collection of inorganic magnetite, maghemite, greigite and altered biogenic samples. Although we have measured just a few strains of MTBs, the data show in convincing fashion that a $\delta_{\mathrm{FC}} / \delta_{\mathrm{ZFC}}$ greater than 2 is a unique magnetic signature for intact chains of unaltered magnetosomes. Furthermore, the $\delta_{\mathrm{FC}} / \delta_{\mathrm{ZFC}}$ ratio can discriminate between intact chains of unaltered magnetite and altered BIM- and BOB-type magnetites in situations where there is very limited influx of inorganic magnetic minerals, or, as in our case, under laboratory conditions. Unfortunately, oxidation of magnetosomes completely obscures the difference in $\delta_{\mathrm{FC}} / \delta_{\mathrm{ZFC}}$ ratios between magnetosomes and inorganic magnetite/maghemite, undermining the diagnostic value of this method under these conditions.

\subsection{Binary mixture model}

Despite the distinct $\delta_{\mathrm{FC}} / \delta_{\mathrm{ZFC}}$ ratios for intact chains of magnetosomes from pure cultures, in order for this ratio to be a practical magnetic method there must still be a detectable magnetosome response when there is a mixture of bio- 
genic and abiogenic magnetite present. To test the diagnostic capabilities of $\delta_{\mathrm{FC}} / \hat{\delta}_{\mathrm{ZFC}}$ ratios under more realistic conditions, a simple binary mixture model was developed using our experimental low-temperature data. Full details of the model are given in the Appendix. The mixing model consists of two components. These are represented by a biogenic fraction of intact chains of unaltered magnetite magnetosomes and a "non-chain" fraction consisting of any one of the following: (1) either SD, PSD, or MD inorganic magnetite grains: (2) SPM grains of inorganic or BIM-type magnetite, maghemite, or greigite; (3) inorganic or BOB-type maghemite; and (4) inorganic or BOB-type greigite. The term "non-chain" fraction is used here to include any inorganic fraction, as well as oxidized or greigite magnetosomes. With the assumptions outlined in the Appendix, the $\delta_{1,} / \delta_{Z F C}$ ratio for a two-component mixture is:

$$
\begin{aligned}
\frac{\delta_{\mathrm{FC}}}{\delta_{\mathrm{ZFC}}}= & \frac{0.5 m+(1-m) j_{\mathrm{a}}}{0.6 m+(1-m) j_{\mathrm{a}}}\left(\frac{\delta_{\mathrm{FC}}}{\delta_{\mathrm{ZFC}}}\right)_{\mathrm{h}} \\
& \times\left[\frac{0.6 m+5 R_{\mathrm{a}}(1-m) j_{\mathrm{at}} \delta_{\mathrm{a}}}{0.5 m+12.5(1-m) j_{\mathrm{it}} \delta_{\mathrm{a}}}\right]
\end{aligned}
$$

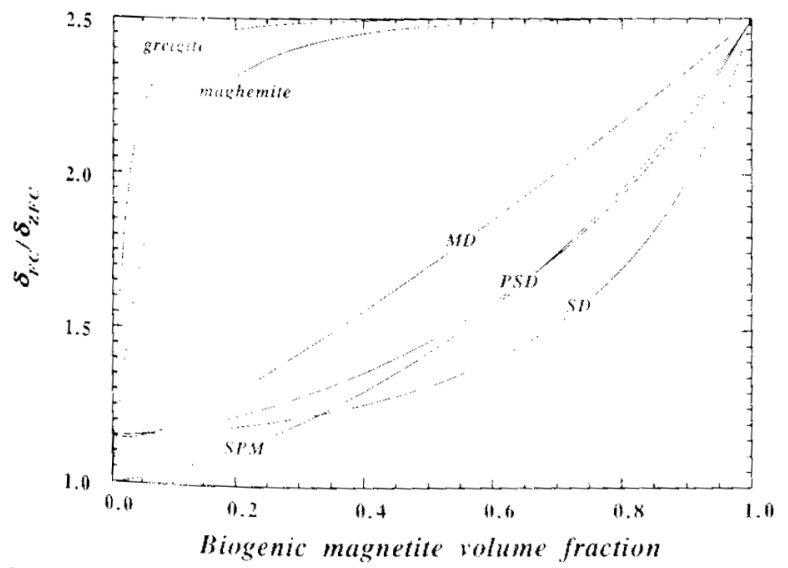

Fig. 12. The oforof parameter as a function of biogenic volume fraction for a two-component mixture model. The biogenic fraction consists of intact chains of magnetite magnetosomes and the "non-chain" fractions consist of any one of the following components: (1) superparamannetic grains (SPM); (2) silygle domain grains (SD): (3) pseudo-single domain grain (PSD): (4) multidomain grains (MD); (5) maghemite: of (6) greigite. Sec text and appendix for details. where $m=$ the biogenic chain fraction; $j_{\mathrm{a}}=\mathrm{SIRM}$ at $80 \mathrm{~K} ; \delta_{\mathrm{a} a}=\mathrm{ZFC}$ ratio; $R_{\mathrm{at}}=\delta_{\mathrm{FC}} / \delta_{\mathrm{ZFC}}$; and the subscripts $\mathrm{a}$ and $\mathrm{b}$ denote parameters for nonchain and chain fractions, respectively. Fig. 12 summarizes the results of these calculations and leads to the following three cases and likely scenarios where they may be applicable.

Case 1: Mixtures of chains and maghemite/ greigite. The first case considers a mixtures of chains and maghemite or greigite. For this case, $\delta_{\mathrm{FC}} / \delta_{\mathrm{ZFC}}$ at first increases rapidly with increasing chain fraction then approaches the limiting chain value of 2.5 around $m=0.5$ (Fig. 12). This behavior is not too surprising since the very low $\delta$ values $(<0.05)$ for maghemite and greigite make the magnetite transition stand out against a nearly linear background for low chain fractions. At high chain fractions the transition behavior dominates and the sensitivity to chain fraction is lost. A possible natural setting where this particular case may apply is in Holocene carbonate sediments, like those in the Great Bahama Bank [8]. Because there is limited influx of abiogenic magnetic minerals into this area, most of the finegrained magnetite/maghemite being deposited is believed to be of biogenic origin [8]. Under these conditions, our method may prove useful as an index for the degree of chemical alteration of magnetosome chains after deposition. Another natural setting that may approximate the conditions of this first case is a present day sulfidic environment, such as a salt marsh or stratified anaerobic coastal pond that contains both greigite and magnetite MTBs $[5,13]$. In these environments, our method may be useful in quantifying the amounts of magnetite and greigite in surface sediments produced by magnetotactic bacteria or in estimating magnetite/greigite bacterial populations from enrichment cultures collected at discrete water depths.

Case 2: Mixture of chains and BIM-type magnetic particles. This second case considers a mixture of chains and BIM-type superparamagnetic particles. The SPM particles can be magnetite, greigite or maghemite. For mixtures of this type. $\delta_{\mathrm{FC}} / \delta_{\mathrm{ZFC}}$ is roughly linear for both low and high chain fractions (Fig. 12). A natural setting where this case may be applicable is in suboxic marine 
sediments, where authigenic or biogenic magnetite formation occurs between the zones of nitrate reduction and iron reduction [47]. If magnetite production is biologically mediated in these sediments, our method could provide information on the fractions of BOB- and BIM-type magnetite produced within the zone of magnetite formation.

Case 3: Mixtures of chains and SD, PSD or MD magnetite. The last case considers a mixture of chains and either SD, PSD or MD magnetite. This is the most common case of the binary mixture model and could apply to many different marine settings [29]. In this case, identification of a chain component relies strongly on the experimentally observed differences between FC and ZFC behavior for chains and inorganic magnetite. Unlike the previous two cases, where the non-chain fractions do not have remanence transitions, in this case both fractions have transitions. A positive chain response is indicated when $\delta_{\mathrm{FC}} / \delta_{\mathrm{ZFC}}$ is above a certain threshold value. A reasonable value for this threshold is 1.5 , approximately $20 \%$ higher than the average pure inorganic value for $\delta_{\mathrm{FC}} / \delta_{\text {ZFC }}$ (see Appendix). As the curves in Fig. 12 show, unless the chain fraction exceeds $40-50 \%$ for either the MD or PSD fractions, a positive chain response may be difficult to identify using $\delta_{\mathrm{FC}} / \delta_{\mathrm{ZFC}}$ values alone. The situation is even worse for SD fractions, for which the chain fraction must exceed $75 \%$ for a positive response to be identified unambiguously.

\section{Discussion and conclusions}

We have measured several rock magnetic parameters for biogenic magnetites from bacteria grown in axenic culture. Although there are only a limited number of axenic cultures of MTBs available for study, we have identificd four magnetic propertics that may be useful for detecting the presence of biogenic SD magnetite in the form of intact magnetosome chains in sediments. The diagnostic rock magnetic parameters are:

(1) $R_{\mathrm{df}} \approx 0.5$

(2) $R_{\text {iff }}>0.5$;
(3) $\mathrm{ARM} / \mathrm{SIRM}=0.15-0.25$

(at $\mu_{0} H_{\text {applied }}=0.1 \mathrm{mT}$ );

(4) $\delta_{\mathrm{FC}} / \delta_{\mathrm{ZFC}}>2$.

This combination of magnetic properties for whole-cell samples is due to several interrelated factors connected to the unique features of BOB-type magnetite. Properties (1) and (3) result from the negligible dipolar interactions between SD magnetosome chains. Property (2) is a timedependent effect reflecting the specific SD vol. ume distribution of magnetosomes. Property (4) is due to the novel arrangement of magnetosomes in linear chains.

The $R_{\text {af }}$ parameter is obtained from analysis of the acquisition and demagnetization of IRM. When static field and AF curves are plotted in normalized form, the crossover point $R_{\mathrm{af}}$ is greater than 0.5 for intact chains of magnetosomes. This apparent shift in $R_{\text {af }}$ to values greater than 0.5 is due to a time-dependent effect, caused by the difference in field switching frequencies between $\mathrm{AF}$ and static fields and the narrow distribution of SD magnetosome volumes. When pulse fields are used instead of static fields, this "time shift" in $R_{\text {af }}$ disappears and one obtains the standard result ( $R_{\text {af }}=0.5$ ) for non-interacting particles. The $R_{\text {af }}$ shift is a unique property of the specific volume distribution of the magnetosomes and the minimal effects of chain interactions. Other inorganic SD magnetite or maghemite can be non-interacting, but they may not have the right volume distribution to produce a noticeable "time shift" in the coercivity distribution using standard paleomagnetic equipment. Disruption of the chain and maghemitization of magnetosomes also masks the "time shift". Although there are reports of sediments containing biogenic magnetite for which $R_{\text {af }} \approx 0.4-0.5[6,8]$, there have been none reported with $R_{\text {af }}>0.5$. This is not surprising because most studies on biogenic magnetite in sediments use pulse magnetization methods so the "time shift" would be completely missed. However, of more serious concern is the possibility that mixtures of biogenic and inorganic magnetic phases in such sediments may negate the diagnostic value of the Wohlfarth-Cisowski test.

High ratios of ARM/SIRM, ranging from 15\% 
$1025 \%$ for an inducing field of $0.1 \mathrm{mT}$, are also a characteristic property of intact chains of magnetosomes in freeze-dried and wet cells, resulting from the $\mathrm{SD}$ sizes of magnetosomes and negligible chain-chain demagnetizing interactions. $A R M / S I R M$ ratios in this range, however, are not unique to magnetosome chains but have been also observed in rocks and synthetic analogs consisting of non-interacting SD particles $[37,39,48]$. Nevertheless, high ARM/SIRM ratios, in combination with $R_{\text {it }}$ parameters greater than 0.5 , form a set of characteristic magnetic parameters which is unique for intact chains of magnetosomes. The question that remains to be answered is whether this combination of parameter values is truly diagnostic of biogenic magnetite or just non-interacting SD particles with volume distributions similar to those of magnetosomes produced by MTBs?

The $\delta_{\mathrm{FC}} / \delta_{\text {ZFC }}$ parameter is potentially the most diagnostic of the magnetic measurements discussed. Unlike the ARM/SIRM and $R_{\text {af }}$ parameters which are sensitive to the specific particle volume distribution of magnetosomes, the difference between low-temperature $\mathrm{FC}$ and $\mathrm{ZFC}$ SIRMs on warming through the Verwey transition depends on the unique chain arrangement of magnetite magnetosomes in magnetotactic bacteria. Two features of the chain are responsible for the observed behavior. First, the magnetosomes are pure magnetite so they will undergo the crystallographic transformation near $100 \mathrm{~K}$. Second, the parallel alignment of the $\langle 111\rangle$ directions along the chain direction enhances the effects of the field-induced alignment of the monoclinic $c$ axes below the Verwey transition, resulting in a higher SIRM and a greater loss in remanence at $T_{v}$ than in the ZFC case. Our results show that intact chains of unoxidized magnetite magnetosomes have ratios of $\delta_{\mathrm{FC}} / \delta_{\mathrm{ZFC}}$ greater than 2 . Disruption of the chain structure, or conversion of the magnetosomes to maghemite, reduces the $\delta_{\mathrm{FC}} / \delta_{\mathrm{ZFC}}$ ratio to near 1 , similar to values we observed from our collection of inorganic magnetite, maghemite and greigite. Numerical simulations of $\delta_{\mathrm{FC}} / \delta_{\mathrm{ZFC}}$ ratios for two-phase systems modeled as a simple binary mixture of chain (BOB-typc magnetite) and non-chain fractions (inorganic or oxidized BIM- or BOB-type) suggest that the $\delta_{\mathrm{FC}} / \delta_{\mathrm{ZFC}}$ parameter is useful for distinguishing chain from non-chain contributions under certain conditions satisfied by several natural environments.

It should be kept in mind that magnetotactic bacteria are diverse, with just a few species studied in any detail. They produce a variety of magnetosome shapes and arrangements within cells. In some species, magnetosomes are not even arranged in chains and there has yet to be any magnetic study on greigite magnetosomes or magnetosomes with elongated cubo-octahedra morphology, exhibiting bullet-shape, tear-drop and arrowhead forms. In view of these limitations, as well as complications arising from mixtures of biogenic and inorganic magnetic phases, it is uncertain how robust the $\delta_{\mathrm{FC}} / \delta_{\mathrm{ZFC}}$ parameter will be for detecting biogenic magnetite from MTBs in sediments for typical situations. We can predict one situation where our method will fail to detect the presence of chains of magnetite magnetosomes, even in pure culture. Vali and Kirschvink [16] observed a species of magnetotactic bacteria that produces arrowhead-shaped magnetosomes aligned parallel to their [100] directions. In this case, we predict that the remanence transition will be suppressed because there would be no switch in the easy axis on cycling through the Verwey transition, a result indistinguishable from the behavior of maghemite or greigite. Fortunately, these type of magnetosomes appear to be very rare [16].

On a more positive note, our results suggest that the $\delta_{\mathrm{FC}} / \delta_{\mathrm{ZFC}}$ parameter can be highly diagnostic of biogenic magnetite in the form of intact chains of magnetite magnetosomes and can be a useful magnetic technique for identifying them in whole-sediment samples. The strength of our approach lies in the comparative ease and rapidity with which magnetic measurements can be made compared to techniques such as electron microscopy. Examples of situations where our method could be tested and prove useful are: (1) modern marine carbonate environments, such as the Great Bahama Bank: (2) magnetite formation in suboxic marine sediments between zones of nitrate reduction and iron reduction; and (3) pre- 
Table 1

Model parameters for non-chain fraction

\begin{tabular}{lccc}
\hline \multicolumn{1}{c}{ Non-chain Fraction } & $j_{\mathrm{a}}$ & $\delta_{\mathrm{a}}$ & $\mathrm{R}_{\mathrm{a}}$ \\
\hline $\mathrm{Fe}_{3} \mathrm{O}_{4}: \mathrm{SD}$ & 0.5 & 0.4 & 1.15 \\
$\mathrm{Fe}_{3} \mathrm{O}_{4}: \mathrm{PSD}$ & 0.2 & 0.5 & 1.15 \\
$\mathrm{Fe}_{3} \mathrm{O}_{4}: \mathrm{MD}$ & 0.05 & 0.9 & 1.15 \\
$\mathrm{Fe}_{3} \mathrm{O}_{4}: \mathrm{SPM}$ & 0.15 & 0.55 & 1.0 \\
$\gamma-\mathrm{Fe}_{2} \mathrm{O}_{3}: \mathrm{SD} / \mathrm{PSD}$ & 0.16 & 0.02 & 1.0 \\
$\mathrm{Fe}_{3} \mathrm{~S}_{4}: \mathrm{SD} / \mathrm{PSD}$ & 0.05 & 0.02 & 1.0 \\
\hline
\end{tabular}

sent day sulfidic environments such as salt marshes and stratified anaerobic coastal ponds.

\section{Acknowledgements}

RBF and DAB were supported by the Office of Naval Research contract N00014-91-j-1290. DAB was also supported by National Science Foundation contract MCB-9117694. BMM was supported by National Science Foundation contract EAR-8904380. Support for the IRM is provided by grants from the Keck Foundation and the National Science Foundation. This is contribution 9305 of the Institute for Rock Magnetism.

\section{Appendix}

Equation (2) in the text is derived as follows. We assume a sediment sample contains a binary mixture of volume fractions of magnetite magnetosome chains and "non-chain" magnetic phases. The "non-chain" fraction is any one of the following: (1) either SD, PSD or MD inorganic magnetite grains; (2) SPM grains of inorganic or BIM-type magnetite, maghemite or greigite; (3) inorganic or BOB-type maghemite; or (4) inorganic or BOB-type greigite. As used here, the term "non-chain" fraction includes any inorganic fraction as well as oxidized and greigite magnetosomes.

The total saturation remanence, $J_{\text {sirm }}$, at temperature $T$ is:

$J_{\text {sirm }}=m j_{\text {sirm }}^{\mathrm{h}}+(1-m) j_{\text {sirm }}^{\mathrm{a}}$ where $m=$ the volume fraction of chains; $j_{\text {sirm }}=$ the saturation remanence of the pure fraction, and the superscripts a and b refer to the non-chain and chain fractions. After some manipulation, the $\delta$ parameter (see Eq. (1) in the text) for the two-component mixture is:

$\delta=\frac{m \delta^{\mathrm{b}} j_{\mathrm{sirm}}^{\mathrm{b}}(80)+(1-m) \delta^{\mathrm{a}} j_{\text {sirm }}^{\mathrm{a}}(80)}{m j_{\mathrm{sirm}}^{\mathrm{b}}(80)+(1-m) j_{\mathrm{sirm}}^{\mathrm{a}}(80)}$

Using Eq. (4), the $\delta_{\mathrm{FC}} / \delta_{\mathrm{ZlC}}$ ratio for the mixture is:

$$
\begin{aligned}
\frac{\delta_{\mathrm{FC}}}{\delta_{\mathrm{ZFC}}}= & \frac{m j_{\mathrm{ZfC}}^{\mathrm{b}}+(1-m) j_{\mathrm{zfc}}^{\mathrm{a}}}{m j_{\mathrm{fc}}^{\mathrm{b}}+(1-m) j_{\mathrm{fc}}^{\mathrm{a}}}\left(\frac{\delta_{\mathrm{fc}}^{\mathrm{b}}}{\delta_{\partial \mathrm{fc}}^{\mathrm{b}}}\right) \\
& \times\left[\frac{m j_{\mathrm{fc}}^{\mathrm{b}}+(1-m) j_{\mathrm{fc}}^{\mathrm{a}}\left(\delta^{\mathrm{a}} / \delta^{\mathrm{b}}\right)_{\mathrm{fc}}}{m j_{\mathrm{zfc}}^{\mathrm{b}}+(1-m) j_{z \mathrm{fc}}^{\mathrm{a}}\left(\delta^{\mathrm{a}} / \delta^{\mathrm{b}}\right)_{\mathrm{zfc}}}\right]
\end{aligned}
$$

where $j$ is the SIRM at $80 \mathrm{~K}$ and the sirm subscript has been dropped. From our low temperature SIRM measurements. we have the following average parameter values for the $b$, or chain fraction: $\left\langle\delta_{\mathrm{fc}}\right\rangle=0.2 ;\left\langle\delta_{\mathrm{ffc}}\right\rangle=0.08 ; \delta_{\mathrm{fc}} / \delta_{\mathrm{zfc}}$ $=2.5 ; j_{\text {zfc }}=0.5 J_{\mathrm{s}} ; j_{\mathrm{fc}}=0.6 J_{\mathrm{s}}$, where $J_{\mathrm{s}}$ is the saturation magnetization for magnetite. Using these values in Eq. (5), we obtain Eq. (2):

$$
\begin{aligned}
\frac{\delta_{\mathrm{FC}}}{\delta_{\mathrm{ZFC}}}= & \frac{0.5 m+(1-m) J_{\mathrm{a}}}{0.6 m+(1-m) J_{\mathrm{i}}}\left(\frac{\delta_{\mathrm{FC}}}{\delta_{\mathrm{ZFC}}}\right)_{\mathrm{b}} \\
& \times\left[\frac{0.6 m+5 R_{\mathrm{a}}(1-m) J_{\mathrm{a}} \delta_{\mathrm{a}}}{0.5 m+12.5(1-m) J_{\mathrm{il}} \delta_{\mathrm{a}}}\right]
\end{aligned}
$$

where $\delta_{\mathrm{a}}=$ ZFC ratio; $R_{\mathrm{a}}=\delta_{\mathrm{fc}} / \delta_{\mathrm{zfc}} ;$ and $j_{\mathrm{a}}=j_{\mathrm{zfc}}$ $\approx j_{\mathrm{fc}}$. Values for $\delta_{\mathrm{a}}, R_{\mathrm{a}}$ and $j_{\mathrm{at}}$ are dependent on the non-chain mineral phase and its grain size; average values are given in Table 1 . 
Eq. (6) is subject to the following assumptions. The slight thermal change in SIRM between $20 \mathrm{~K}$ and $80 \mathrm{~K}$ is ignored, except for the SPM model values. We approximate the SIRM value at $80 \mathrm{~K}$ for the pure fraction, from SIRM $/ J_{s}$ values that are typical for SD (0.5), PSD (0.2) and MD (0.05) grains. Finally, an additional correction factor for $j_{a}$ is applied for maghemite and greigite models to account for the lower $J_{\mathrm{s}}$ values for these phases. The correction factors are 0.8 and 0.25 for maghemite and greigite, respectively.

\section{References}

[1] J.L. Kirschvink and H.A. Lowenstam, Magnetization of chiton teeth: paleomagnetic, sedimentologic, and biologic implications of organic magnetite. Earth Planet. Sci. Lett. 44, 193-2(1). 1979.

[2] H. Vali. O. Forster, G. Amarantidis and N. Petersen, Magnetutactic bacteria and their magnetofossils in sediments. Farth Planet. Sci. Lett. 86, 389-400, 1987.

[3] S.-B.R. Chang and J.L. Kirschvink, Magnetofossils, the magnetiration of sediments, and the evolution of magnetite hiomineralization. Annu. Rev. Earth Planet. Sci. $17,169-195,1989$.

[4] J.F. Stols. D.R. Lovley and S.E. Haggerty, Biogenic magnetite and the magnetization of sediments, J. Geophys. Res. 95B. 4.355-4361, 1990.

[5] A. Demitrack, A search for bacterial magnetite in the sediments of Eel Marsh, Woods Hole, Massachusetts. in: Magnetite Biomineralization and Magnetoreception in Organisms: A New Biomagnetism. J.L. Kirschvink, D.S. Jones and B.J. Macfadden, eds., pp. 625-645. Plenum, New York, 1985.

[6] J.F. Stoly. S.-B.R. Chang and J.L. Kirschvink. Magnetotactic bacteria and single-domain magnetite in hemipulagic sediments, Nature 321,849-850, 1986.

[7] S.-B.R. Chang, J.L. Kirschvink and J.F. Stolz. Biogenic magnetite as a primary remanence carrier in limestone deposits. Phys. Earth Planet. Inter. 46, 289-303, 1987.

[8] D.F. McNeill. Biogenic magnetite from surface Holocene carbonate sediments, Great Bahama Bank. J. Geophys. Res. 95B. 4363-4372, 1990.

[9] J.L. Kirschvink and S.-B.R. Chang. Ultrafine-grained magnetite in deep-sea sediments: possible bacterial magnetofossils, Geology 12, 559-562, 1984.

[10] N. Petersen. T. von Dobeneck and H. Vali, Fossil bacterial magnetite in deep-sea sediments from the South Atlantic Ocean, Nature 320, 611-615, 1986.

11] R.P. Blakemore, Magnetotactic bacteria. Annu. Rev. Microbiol. 36, 217-238, 1982

[12] R.B. Frankel, Magnetic guidance of organisms, Annu. Rev. Biophys. Bioeng. 13,85-103, 1984.
[13] D.A. Bazylinski. R.B. Frankel. A.J. Garratt-Reed and S. Mann. Biomineralization of iron sulfides in magnetotactic bacteria from sulfidic environments, in: Iron Biominerals. R.B. Frankel and R.P. Blakemore, eds,, pp. 239255, Plenum, New York, 1990.

[14] J.W.E. Fassbinder. H. Stanjek and H. Vali, Occurrence of magnetic bacteria in soil, Nature 343,161-163, 1990.

[15] S. Mann and R.B. Frankel, Magnetite biomineralization in unicellular organisms. in: Biomineralization: Chemical and Biochemical Perspectives, S. Mann, J. Webb and R.J.P. Williams, eds.. pp. 389-426, VCH, New York, 1989.

[16] H. Vali and J.L. Kirschvink. Observations of magnetosome organization, surface structure, and iron biomineralization of undescribed magnetic bacteria: evolutionary speculations, in: Iron Biominerals, R.B. Frankel and R.P. Blakemore, eds., pp. 97-115. Plenum. New York, 1990.

[17] F.C. Meldrum. S. Mann, B.R. Heywood. R.B. Frankel and D.A. Bazylinski, Electron microscopy study of mag netosomes in two cultured vibrioid magnetotactic bacteria. Proc. R. Soc. London Ser. B 251, 237-242, 1993.

[18] F.C. Meldrum, S. Mann, B.R. Heywood, R.B. Frankel and D.A. Bazylinski. Electron microscopy study of magnetosomes in a cultured coccoid magnetotactic bacterium. Proc. R. Soc. London Ser. B 251, 231-236, 1993.

[19] N.H.C. Sparks, S. Mann. D.A. Bazylinski, D.R. Lovley, H.W. Jannasch and R.B. Frankel, Structure and morphology of magnetite anaerobically-produced by a marine magnetotactic bacterium and a dissimilatory iron-reducing bacterium, Earth Planet. Sci. Lett. 98, 14-22, 1990.

[20] D.R. Lovley, J.F. Stolz, G.L. Nord Jr. and E.J.P. Phillips, Anaerobic production of magnetite by a dissimilatory iron-reducing microorganism. Nature 330. 252-254. 1987.

[21] D.R. Lovley, Magnetite formation during microbial dissimilatory iron reduction, in: Iron Biominerals, $\mathrm{R} B$. Frankel and R.P. Blakemore. eds., pp. 151-166. Plenum, New York. 1990.

[22] R.B. Frankel, Anaerobes pumping iron. Nature 330. 208. 1987.

[23] D.T. Rickard. The microbiological formation of iron sulfides, Stockholm Contrib. Geology 20, 50-66, 1969.

[24] R.F. Butler and S.K. Banerjee. Theoretical single-domain grain size range in magnetite and titanomagnetite. $J$. Geophys. Res. 8(). 4049-4058. 1975

[25] B.M. Moskowitz, R.B. Frankel. D.A. Bazylinski, H.W Jannasch and D.R. Lovley, A comparison of magnetite particles produced anaerobically by magnetotactic and dissimilatory iron-reducing bacteria. Geophys. Res. Lett 16. $665-668,1989$

[26] S. Mann. N.H.C. Sparks. S.B. Couling. M.C. Larcombe and R.B. Frankel. Crystallochemical characterization of magnetic spinels prepared from aqueous solution. J Chem. Soc. Farad. 85, 3033-3045, 1989

[27] B.A. Maher and R.M. Taylor, Formation of ultrafine grained magnetite in soils. Nature 336. 368-371, 1988.

[28] B.M. Moskowitz, R.B. Frankel. P.J. Flanders, R.P Blakemore and B.B. Schwartz. Magnetic properties of 
magnetotactic bacteria, J. Magn. Magn. Mater. 73, 273$288,1988$.

[29] H. Vali, T. von Dobeneck, G. Amarantidis, O. Forster, G. Morteani, L. Bachmann and N. Petersen, Biogenic and lithogenic magnetic minerals in the Atlantic and Pacific deep sea sediments and their paleomagnetic significance, Geol. Rundsch. 78 (3), 753-764, 1989.

[30] D.A. Bazylinski, Anaerobic production of single-domain magnetite by the marine, magnetotactic bacterium, strain MV-1, in: Iron Biominerals, R.B. Frankel and R.P. Blakemore, eds., pp. 69-77, Plenum, New York, 1990.

[31] R.P. Blakemore, D. Maratea, and R.S. Wolfe, Isolation and pure culture of a freshwater magnetic spirillum in chemically defined medium, J. Bacteriol. 140, 720-729, 1979.

[32] R.V. Morris, H.V. Lauer, Jr., C.A. Lawson, E.K. Gibson Jr., G.A. Nace and C. Stewart, Spectral and other physicochemical properties of hematite $\left(\alpha-\mathrm{Fe}_{2} \mathrm{O}_{3}\right)$, maghemite $\left(\gamma-\mathrm{Fe}_{2} \mathrm{O}_{3}\right)$, magnetite $\left(\mathrm{Fe}_{3} \mathrm{O}_{4}\right)$, goethite $(\alpha-\mathrm{FeOOH})$, and lepidocrocite $(\gamma$-FeOOH), J Geophys. Res. 90, 31263144, 1985.

[33] Ö. Özdemir and S.K. Banerjee, A preliminary magnetic study of soil samples from west-central Minnesota, Earth Planet. Sci. Lett. 59, 393-403, 1982.

[34] D.J. Dunlop, Hysteresis properties of magnetite and their dependence on particle size: a test of pseudo-single-domain remanence models, J. Geophys. Res. 91B. $9569-$ 9584, 1986.

[35] Ö. Özdemir, D.J. Dunlop, and B.M. Moskowitz, The effect of oxidation on the Verwey transition in magnetite, Geophy. Res. Lett., in press, 1993.

[36] M. Krs, M. Krosva, P. Pruner, A. Zeman, F. Novak and J. Jansa, A petromagnetic study of Miocene rocks bearing micro-organic material and the magnetic mineral greigite (Sokolov and Cheb basins, Czechoslovakia), Phys. Earth Planet. Inter. 63, 98-112, 1990.

[37] D.J. Dunlop, Coercive forces and coercivity spectra of submicron magnetites, Earth Planet. Sci. Lett. 78, 288.
295, 1986.

[38] E.P. Wohlfarth, Relations between different modes of acquisition of the remanent magnetization of ferromag. netic particles, J. Appl. Phys. 35. 595-596, 1958.

[39] S. Cisowski, Interacting vs. non-interacting single-domain behavior in natural and synthetic samples, Phys. Earth Planet. Inter, 26, 77-83, 1981.

[40] P.J. Flanders and M.P. Sharrock. An analysis of time-dependent magnetization and coercivity and their relationship to print-through in recording tapes, J. Appl. Phys. 62, 2918-2928, 1987.

[41] B.A. Maher, Magnetic properties of some synthetic sub. micron magnetites, Geophys. J. 94. 83-96, 1988.

[42] H. Vali and J.L. Kirschvink. Magnetofossil dissolution in a paleomagnetically unstable deep-sea sediment, Nature 339, 203-206, 1989.

[43] F.D. Stacey and S.K. Banerjee, The Physical Principles of Rock Magnetism, 195 pp.. Elsevier. Amsterdam, 1974.

[44] M.R. Spender, J.M.D. Coey and A.H. Morrish, The magnetic properties and Mössbauer spectra of synthetic samples of $\mathrm{Fe}_{3} \mathrm{~S}_{4}$, Can. J. Phys. 50, 2313-2326, 1972.

[45] N. Otsuka and H. Sato, Observation of the Verwey transition in $\mathrm{Fe}_{3} \mathrm{O}_{4}$ by high-resolution electron microscopy, J. Solid State Chem. 61, 212-222, 1986.

[46] F. Heider, D.J. Dunlop and H.C. Soffel, Low-temperature and alternating field demagnetization of saturation and thermoremanence in magnetite grains $(0.037 \mu \mathrm{m}$ to 5 mm), J. Geophys. Res. 97, 9371-9381. 1992.

[47] R. Karlin, M. Lyle and G.R. Heath. Authigenic magnetite formation in suboxic marine sediments, Nature 326, 490-493, 1987.

[48] M. Jackson, P. Rochette, G. Fillion. S.K. Banerjee and J. Marvin. Rock magnetism of remagnetized paleozoic carbonates: Low-temperature behavior and susceptibility characteristics, J. Geophy. Res. 98. 6217-6255, 1993. 